the ingestion of sulphur began; and, though I cannot positively connect the two facts as cause and effect, I have little doubt of their standing in that relation to each other. Wishing, as far as possible, to clear up the matter, I then and there laid a positive interdict upon the use of "flowers of sulphur," let the complexion suffer ever so much in consequence; ordered the bromide mixture to be discontinued, and, recommending plenty of out-door exercise, took my leave, convinced in my own mind that I had discovered the matcries morbi of epilepsy in this case at least. I have only to say, in conclusion, that there has been no recurrence of the attacks since; that Kate - continues in the enjoyment of perfect health, all her functions are performed with healthy regularity, and her complexion is far more brilliant than when she was taking the large doses of sulphur to improve it.

\section{CASES IN SURGERY.}

\section{By THOMAS BROWN, M.R.C.S., La Poile, Newfoundland.}

Wound of the Left Hand.-William Ellis, a trapper and furrier, was firing a gun at some game, when it burst in his hands near the muzzle, inflicting a severe wound, fracturing several of the phalanges of the thumb and index finger, also some of the metacarpal bones. There was also considerable displacement in others; the dorsal ligaments were seriously injured. At the time of the accident, the man was far away from surgical aid; and it was several weeks after the accident occurred when he came for my advice. At this time, the wound presented a very repulsive appearance; sloughing of the soft parts had been going on for some time, and several of the displaced metacarpal bones were necrosed; exfoliation had also to some extent taken place. The gangrenous aspect extended to the wrist. The man suffered excruciating pain; and he earnestly requested the removal of the hand. I acceded to his wishes at once (solus), and amputated the hand at the lower third of the forearm, under the effectual influence of chloroform. A good stump, covered with a fair cushion, was the result; and in six weeks my patient was following his usual occupation.

Strumous Degeneration of the Knee-Foint.-Sarah Matthews, aged 21, living at Petites, on the western shore of this island, consulted me for disease of the knee-joint, resulting from the disastrous practice of cleaning floors in the bent position. It was gathered from the history of the case, which had been in existence some years, that violent and repeated attacks of inflammation had terminated in suppuration within the joint. Various applications had previously been employed; but, in the absence of rest in the recumbent position, no reparative operation, such as ankylosis, could reasonably be anticipated. On examination, I found extreme tumefaction; neither flexion nor extension could be employed. On manipulating the limb, I could produce slight motion, but it was attended with considerable pain. Several small eliminating abscesses presented themselves near the patella and over the internal and external condyles. The patient's appearance was haggard in the extreme; there was hectic fever, rapid atrophy of the tissues, and a very short and miserable existence alone remained for the patient, if surgical assistance were not at once resorted to. In compliance with her importunate request, I amputated the leg (under the influence of chloroform) by the flap-operation, midway between the diseased joint and the head of the femur. Cicatrisation was complete in one month, and robust health was the result.

\section{AN UNUSUALLY LARGE HYDROCELE.}

By F. W. GIBSON, M.D.Lond., Assistant Medical Officer, State Asylum, Broadmoor.

THE case is one of unusually large hydrocele occurring in a man aged 6r. Its origin dates as far back as 1857 , at which time the patient was an inmate of Bethlem Hospital; and it was caused, according to his ac. count, by a kick on the right testicle.

On his admission into Broadmoor Asylum in 1865 , the tumour reached a little below his knees; its greatest circumference was thirty-two inches; it contained two cysts, and, on the right side, a large hernia. Until August 1866, it was tapped frequently, the greatest amount of fluid obtained on any one occasion being eleven pints; but at that time the walls of the cysts had become so thick that further operative measures were not deemed advisable. He suffers considerable inconvenience, both from the weight of the mass and from irritation of the skin of the scrotum caused by the constant dribbling of the urine from the completely buried urethra.

\section{REP0RTS}

OF

\section{MEDICAL AND SURGICAL PRACTICE IN THE HOSPITALS OF GREAT BRITAIN.}

\section{ST. GEORGE'S HOSPITAL.}

THREE CASES TREATED BY LISTER'S METHOD WITH CARBOLIC ACID CLINICAL REMARKS.

(Under the care of Mr. Holmes.)

THE three following cases, of which we give short details, were the first treated by Mr. Holmes in the hospital on Mr. Lister's method. In a few clinical remarks, Mr. Holmes entered fully into the principle involved in the plan carried out by Mr. Lister, not only to apply a detergent, slight stimulant, and antiseptic to the exposed surface, but also to exclude air from the part, and thus prevent sloughing and suppuration, which, he believes, are produced by minute organisms floating in the atmosphere. He said that, since the employment of carbolic acid in this manner, Mr. Lister had not suffered in his hospital practice from pyæmia, phagedæna, and the like. Mr. Holmes had followed out the treatment in a very limited number of cases; far too small, however, to form any conclusive opinion. One of the cases had proved very unfortunate, and would, he believed, have done better without Lister's method. The others had done well; but he thought they would have turned out as satisfactorily by simple means. He thought the method confined the part too much; and that it was impossible to ascertain what was going on below the dressing, which, from the first, ought not to be removed. Considering, however, the high authority who introduced this novel method of applying carbolic acid, and in whose hands it had proved so successful, he intended giving it a full and fair trial.

CASE I. - A boy was admitted on November Ist with a wound on the inner malleolus. The lower end of the malleolus and astragalus seemed denuded. There was a good deal of swelling around. His foot was placed on an outside splint, which at first caused pain. The wound was put up thoroughly according to the directions given by Mr. Lister. On the $4^{\text {th }}$, he felt sick, and the heel was tense and swollen. The swelling had increased by the 7 th; there was a blush up the veins; the skin over the malleolus had given way; and a quantity of pus had collected in a bag at the heel. The carbolic acid treatment was discontinued. The soft parts sloughed away. The leg was amputated; but the case terminated fatally.

CASE II. - This was an injury of a similar nature. The patient, aged 25 , was admitted on November 15 th with a large lacerated wound commencing about an inch above the external malleolus and extending down to the point of the heel. The lower end of the fibula and os calcis were exposed, but not denuded of their periosteum. There was considerable hæmorrhage; but no vessel required to be tied. After the bleeding had ceased, the wound was treated after Lister's method. Next day, there was burning pain over the inner malleolus, and slight oozing of blood from the wound; which was followed, on the 17 th, by a little redness around the wound, extending a short distance up the leg. The pulse was natural. The leg was raised and put in a Salter's swing. Two days afterwards, all signs of inflammation and discharge had disappeared. The oozing appeared again, however, on the 2Ist, without fotor or pain; and continued more or less copious and purulent, with occasional puffiness of the foot until December 3 rd, when the dressings were removed, leaving a healthy and granulating wound.

CASE III. - A boy, aged 16, was admitted on November 15 th, with a large lacerated wound extending round the ball of the thumb, out of which the lacerated ends of muscle were protruding. He had, however, fair motion of the thumb. There was considerable hæmorrhage. Both bones of the forearm were fractured, and considerably displaced. The wound was dressed on Mr. Lister's plan, and the fracture set with a pistol-shaped splint applied to the back of the arm.

Next day, he complained of pain in the wound. The arm and hand were swollen. He was ordered three grains of calomel on the I th, followed by black draught; and, on the following day, the œedema of the arm was less, but there were shooting pains in the hand. The puffi. ness round the wound had increased, and the pulse was 100. However, he slept well, and his appetite was good. On the rgth, there was no oozing or foetor about the wouud. Pulse i 6 . A small vesicle, discharging serous fluid, appeared on the 23rd, at the back of the hand; and there was a slight discharge of pus from under the dressing. The 